\title{
Epistemic Foundations of Political Liberalism ${ }^{1}$
}

Fabienne Peter, Department of Philosophy, University of Warwick,UK

Paper forthcoming in the Journal of Moral Philosophy

This version: September 2012

\section{$\underline{\text { Introduction }}$}

At the core of political liberalism is the claim that political institutions must be publicly justified or justifiable to be legitimate. Public justification is justification by and addressed to all members of the relevant political constituency. Different versions of political liberalism employ different conceptions of public justification, of course, but that is not the main issue I am interested in here. The question I want to focus on instead is: what explains this centrality of public justification?

John Rawls, with whom the idea of political liberalism is most closely associated, argued that the answer to this question lies within political philosophy. According to Rawls, political liberalism finds expression in the "liberal principle of legitimacy". 2 This principle,

\footnotetext{
${ }^{1}$ I am very grateful for the response I have received from participants at the "Epistemic Life of
} Groups" workshop in London, the "Authority, Legitimacy, and Legality" conference in Vienna, the Association of Social and Legal Philosophy annual meeting at Warwick, the philosophy colloquium at the University of York, and the Warwick political philosophy group. For extensive and generous comments, sometimes in written format, I especially want to thank Thomas Baldwin, Matthew Clayton, Miranda Fricker, Sandy Goldberg, Alvin Goldman, Christian List, Matt Matravers, Liam Murphy, Joseph Raz, Massimo Renzo, Hans Bernhard Schmid, Tom Stoneham, Herlinde Pauer-Studer, Victor Tadros, Yann-Allard Tremblay, David Velleman, Catherine Wilson, and, last but not least, anonymous referees. I also want to thank the Leverhulme Trust for a fellowship which has enabled me to do the research for this paper.

${ }^{2}$ John Rawls, Political Liberalism (New York: Columbia University Press, 1993), p. 137. 
which is also the fundamental building block of what he calls a political conception of justice, specifies that the legitimacy of political institutions and the decisions made within them depends on the possibility of justifying them to free and equal citizens. Public justification is necessary for political legitimacy, he argues, because of the irreducible pluralism of moral and/or religious doctrines that characterizes democratic societies. It is sufficient because there are certain fundamental political values that all those living in a democracy can accept and which can serve as the basis for the justification of political institutions and the decisions made within them. Rawls' key idea was that there is a middle way between a narrowly political solution to the problem of legitimacy based on actual acceptance and a moral solution based on the received understanding of justification.

But why should we take pluralism seriously? Critics have argued that Rawls' political strategy, although innovative and fruitful, risks having no arguments to convince those who are not already political liberals in his sense. The worry, which I share, is that Rawls' argument for political liberalism may be too limited. In response, many have been drawn to a moral strategy for overcoming the limitations of the Rawlsian project. They have claimed that liberalism needs moral foundations - either as part of political liberalism or as part of an alternative conception of liberalism. They claim that if pluralism deserves to be taken seriously, it is because of certain moral principles grounded in equal respect, dignity, or autonomy. My main aim in this paper is to argue against this moral strategy and propose an alternative - epistemic - strategy for explaining the significance of public justification.

The paper is organized as follows. In section 2 I give a brief characterization of political liberalism. I shall focus on Rawls' Political Liberalism, the most influential articulation of the idea. ${ }^{3}$ But what I shall have to say in subsequent sections will not be

\footnotetext{
${ }^{3}$ See Thomas Nagel, "Moral Conflict and Political Legitimacy," Philosophy and Public Affairs 16
} (1987): 215-240, for a related view. 
limited to Rawls' conception of it and in fact presents a way of thinking about political liberalism that differs from Rawls' conception. I then present my epistemic argument for the significance of public justification. This argument is rooted in some premises from the epistemology of disagreement (section 3). I then draw out the implications of these premises for the realm of political normativity (section 4).

In a nutshell, I shall argue that the significance of public justification can be explained by the possibility of reasonable disagreement. In a reasonable disagreement, the parties hold mutually incompatible beliefs, but each is justified to hold the belief they do. I shall use the notion of a reasonable disagreement to explain the possibility of an irreducible pluralism of moral and religious doctrines and, on that basis, why the justification of political institutions has to be public. My argument assumes moral realism. I accept the metaphysical claim that there are fundamental moral and/or religious truths that exist independently of our attitudes. So my argument is not based simply on the dismissal of the metanormative claims made by some of Rawls' critics. Instead I will show that the possibility of reasonable disagreements about fundamental moral and religious beliefs implies that the received understanding of justification is not sufficient for establishing political legitimacy.

\section{$\underline{\text { Political Liberalism }}$}

Political liberalism is best understood in contrast with comprehensive liberalism. The distinction hinges on how the requirements of legitimacy and justice are justified. In comprehensive liberalism, these justifications derive from moral or religious doctrines - from "rather precisely articulated systems" that "cover all values and virtues". ${ }^{4}$ In Mill's liberalism, for example, it is the greatest happiness principle that establishes when political institutions and decisions made within them are legitimate and what justice requires. In

\footnotetext{
${ }^{4}$ Rawls, Political Liberalism, p. 13.
} 
political liberalism, by contrast, the justification of the requirements of legitimacy and justice is supposed to draw only on premises that all can share. Public justification thus demands more than valid argument. As Rawls puts it, "when the premises and conclusions are not acceptable on due reflection to all parties in disagreement, valid argument falls short of public justification". 5

How does Rawls explain the importance of public justification? The argument he presents is an argument from disagreement. Political liberalism is a theory for democratic societies. Rawls takes such societies to be committed to the freedom and equality of their citizens and to the fairness of the basic terms of cooperation. In addition, he takes the commitment to these political values to create the fact of "reasonable pluralism". By that he means the inevitable co-existence of incompatible moral and religious doctrines. This situation gives rise to the following problem of legitimacy: "how is it possible to justify political institutions and the decisions made within them to free and equal citizens that are divided by reasonable yet incompatible comprehensive doctrines"? ${ }^{6}$

As I read Rawls, and I think his view is roughly right, he takes legitimacy to require that basic political institutions - the "constitutional essentials" - are justified. This need not mean that each and every decision is justified in the same way. ${ }^{7}$ But the principles that govern the political decision-making process need to be justified if citizens are to have a sufficient reason to support the decisions made within them.

Rawls argues that the solution to the problem of legitimacy is to understand political liberalism as "doctrinally autonomous". According to Rawls, there are doctrine-specific

\footnotetext{
${ }^{5}$ Rawls, Justice as Fairness: A Restatement (Cambridge: Harvard University Press, 2001), p. 27.

${ }^{6}$ Rawls, Justice as Fairness: A Restatement, p. 40f.

${ }^{7}$ Fabienne Peter, Democratic Legitimacy (New York: Routledge, 2009).

${ }^{8}$ Rawls, Political Liberalism, p. 99.
} 
truths and appeals to them are divisive and need to be bracketed. To be successful, justification has to avoid drawing on premises that are not shared across comprehensive doctrines. This is achieved if public justification is free-standing - if it only draws on beliefs that are independent of comprehensive moral and/or religious doctrines.

In sum, Rawls argues that public justification is necessary for legitimacy because deep disagreements between different comprehensive moral and religious doctrines require a mode of justification that stays clear of these disagreements. It is sufficient because of a domain restriction. Since public justification only draws on political values, there will be a broad range of questions for which it will not yield acceptable answers. But, Rawls argues, it will when it comes to the justification of constitutional essentials. ${ }^{9}$

It is an important premise in Rawls' argument for political liberalism that the pluralism of moral and religious doctrines that characterizes democratic societies is "reasonable". Generally put, it is a deep pluralism, not merely a conflict of self-interest. "Reasonable pluralism", in Rawls' use of the term, describes the diversity of doctrines that "reasonable citizens" affirm (1993: 36). "Reasonable" is here to be understood in the context of Rawls' distinction between the reasonable and the rational (1993: 48ff). The distinction is this. Rational persons are able to formulate, revise, and pursue a conception of the good. Persons as reasonable citizens, although committed to a particular comprehensive doctrine of the good, recognize that others may not share their view. When it comes to fundamental political questions, they will abstain from trying to impose their conception of the good on others.

Rawls gives two arguments in support of this claim. First, a sense of justice - in addition to a sense of the good - leads reasonable citizens to be willing to propose fair terms

\footnotetext{
${ }^{9}$ Rawls, Political Liberalism, pp. $227 \mathrm{ff}$.

${ }^{10}$ Rawls, Political Liberalism, p. 36.
} 
of cooperation, as opposed to terms of cooperation which are maximally rational given their own conception of the good. Second, they recognize that the differences between the different comprehensive doctrines cannot be overcome by sufficiently deep rational argumentation. They recognize what Rawls calls "the burdens of judgment". 11

Rawls thus provides a moral and an epistemic argument for the importance of the distinction between the reasonable and the rational and hence for why public justification is necessary for legitimacy in a context of reasonable pluralism. The moral argument is that because citizens have two fundamental moral powers - a sense of justice and a sense of the good - justification in a context of pluralism about the good requires appeal to their sense of justice. The epistemic argument is that because disagreement on questions of the good is possible even after full deliberation, the justification of political institutions requires an alternative basis.

Critics of Rawls' political liberalism have tended to question his account of the significance of public justification and either one or both of his claims about the relation between public justification and political legitimacy. Some critics argue for a moralized conception of liberalism and reject both the claim that public justification is necessary for legitimacy and that it is sufficient. They have been drawn to abandon the very idea of a political conception of justice and legitimacy. Joseph Raz, for example, argues that the idea of political liberalism is "unstable and incoherent" because there is "no middle way between actual (including implied) agreement and rational justification" (Raz 1990: 46). ${ }^{12}$ These critics must reject Rawls' claim that it is important that we pay attention not only to the

\footnotetext{
${ }^{11}$ Rawls, Political Liberalism, pp. 54ff.

${ }^{12}$ Joseph Raz, "Facing Diversity: The Case of Epistemic Abstinence," Philosophy \& Public Affairs, 19
} (1990): 3-46. 
question of what is or can be justified, but also to the question of how anything is or might be justified in societies characterized by reasonable pluralism.

Critics who are more sympathetic to Rawls' overall project have argued that while public justification is necessary, it is not sufficient for political legitimacy. Charles Larmore, for example, argues that the idea of political liberalism is incoherent unless one acknowledges that it rests on the moral principle of equal respect for persons. On his view, it is this principle which explains why we ought to search for reasonable agreement and hence why public justification is important. ${ }^{13}$

Most of Rawls' critics have tended to either neglect or dismiss the epistemic argument for explaining the significance of public justification. ${ }^{14}$ This is probably partly due to the fact that Rawls himself didn't sufficiently develop the epistemic underpinnings of political liberalism. His work does not contain much more than a few sketchy remarks about the burdens of judgment. For this reason it is perhaps not surprising that even many of Rawls' friends have tended to focus on the moral dimension of his work - primarily as developed in A Theory of Justice. ${ }^{15}$

\footnotetext{
${ }^{13}$ Charles Larmore, The Autonomy of Morality (Cambridge: Cambridge University Press, 2008), pp.
} 139ff.

${ }^{14}$ There are exceptions, of course. Gerald Gaus, Justificatory Liberalism (Oxford: Oxford University Press, 1997) has made similar points and I owe a lot to his work. There are also parallels with Robert Talisse's work, see for example his “Toward a Social Epistemic Comprehensive Liberalism,” Episteme 5 (2008): 106128. Neither uses the epistemology of disagreement as starting-point, however. On related topics, see also James Bohman and Henry Richardson, "Liberalism, Deliberative Democracy, and 'Reasons that All Can Accept'," Journal of Political Philosophy 17(2009), 253-274 and Martha Nussbaum, "Perfectionist Liberalism and Political Liberalism”, Philosophy and Public Affairs 39 (2011): 3 - 45.

${ }^{15}$ Leif Wenar, for example, in his much praised critique of Political Liberalism argues that "the burdens of judgment are at best unnecessary for endorsing the content of a liberal view" ("Political Liberalism: 
Against this set of both Rawls' critics and his friends I want to claim that the epistemic argument, properly stated, is crucial for explaining the significance of public justification and hence for political liberalism. I shall argue that public justification is necessary for political legitimacy, but not because of some antecedent moral principle.

\section{The Epistemology of Disagreement}

The political liberal argument for public justification only gets off the ground if widespread disagreement causes a pluralism of opinion that deserves to be taken seriously. But how is disagreement in the political domain best understood? Is reasonable disagreement - i.e. a conflict between beliefs that the parties to the disagreement are each justified to hold possible at all? And if it is, what explains its occurrence? And what does a reasonable disagreement imply for the parties involved?

In the current debate on the epistemology of disagreement, the question whether reasonable disagreement is possible at all is an important topic. One exchange focuses on disagreements that arise after everyone has considered the same body of evidence. The two poles of this debate are marked by positions typically labeled the Equal Weight View and the Steadfast View. ${ }^{16}$ Suppose you find yourself in a disagreement with someone you take to be

An Internal Critique," Ethics 106 (1995): 32 - 62, p. 43. He adds that the epistemic argument may even be detrimental to Rawls' project because it implies a kind of skepticism that would be hostile to the adherents of some moral and religious doctrines. See Jonathan Quong, Liberalism Without Perfection (Oxford: Oxford University Press, 2011) for a Rawlsian response to the skepticism worry.

${ }^{16}$ See David Christensen "Disagreement, Question-Begging, and Epistemic Self-Criticism,” Philosopher's Imprint 11 (http://hdl.handle.net/2027/spo.3521354.0011.006, 2011) for this terminology. In the last couple of years, a number of intermediary positions have emerged; in addition to the article by Christensen I've just mentioned, see also Adam Elga, "How to Disagree about how to Disagree," in Richard Feldman and Ted A. Warfield (eds.) Disagreement (Oxford: Oxford University Press, 2010), pp. 175 - 186, and Thomas Kelly, "Peer Disagreement and Higher Order Evidence," in Richard Feldman and Ted A. Warfield (eds.) 
an epistemic peer. Epistemic peers have (roughly) equal abilities to respond to evidence, which also means that epistemic peers are equally likely to make mistakes. ${ }^{17}$ On the basis of the evidence you've both considered, you formed the belief $\mathrm{p}$ and your peer not-p. Defenders of the Equal Weight View argue that absent any independent reasons to discount the opinion of your peer - say because she complained about a headache earlier - the rational response to such a disagreement is for both of you to revise your beliefs, giving equal weight to the view of the other. ${ }^{18}$ The Equal Weight View implies that people who take each other as peers cannot reasonably disagree in such situations.

The Equal Weight View attaches epistemic significance to the fact that someone who you regard as an epistemic peer disagrees with you after considering the same body of evidence. How can that be motivated? One way is through what is typically labeled the Uniqueness Thesis. ${ }^{19}$ It says that a given body of evidence must favor one doxastic state. In the case of only three doxastic states, Uniqueness implies that the body of evidence after full disclosure must either favor one of two diametrically opposed beliefs or else justify

Disagreement. (Oxford: Oxford University Press, 2010), pp. $111-174$. The debate has moved on towards intermediary positions, but the emphasis has also shifted away from the question whether reasonable disagreement is possible, which is the main question that interests me here, towards the question of how to adequately respond to disagreements. I will focus on the presentation of the extremes, but will comment on some developments in footnotes below.

${ }^{17}$ Adam Elga, "Reflection and Disagreement," Noûs 41(2007): 478-502.

${ }^{18}$ See David Christensen, “Epistemology of Disagreement: The Good News," Philosophical Review 116 (2007): 187-217; Elga "Reflection and Disagreement", and Richard Feldman, "Reasonable Religious Disagreements," in Louise Antony (ed.) Philosophers Without Gods: Meditations on Atheism and the Secular (Oxford: Oxford University Press, 2007), 194 - 214.

${ }^{19}$ Feldman, "Reasonable Religious Disagreements". 
suspension of belief. If two peers assert two diametrically opposed beliefs, since they cannot both be correct, they should both respond to this disagreement by suspending their beliefs.

One way to do get at the possibility of reasonable disagreements is by rejecting the Uniqueness Thesis and adopting a Permissiveness Thesis instead. According to the latter, the overall body of evidence may justify more than one belief. ${ }^{20}$ On this basis, it becomes possible to dismiss the relevance of higher-order evidence about the beliefs of epistemic peers and to argue that the first-order evidence a person has after full disclosure is sufficient to justify belief. ${ }^{21}$ According to defenders of the Steadfast View, the fact that a peer disagrees with you is irrelevant. Because disagreement, even among peers, does not warrant a response, there may thus be cases where the uniquely rational response for both parties to a disagreement is to stick to their original beliefs.

The following examples help explaining the difference between the two views. ${ }^{22}$ Assume you and a friend had a meal in a restaurant. You do this often and you always split the check. You have a look at the check and determine the amount each needs to pay. You then discover that your friend, who also had a look at the check, came up with a different result. Since you and your friend are equally able to do the mental math, the disagreement suggests that you both ought to suspend your belief about what the right amount is. That's the kind of picture that defenders of the Equal Weight View draw. Now consider the following variation of the example. Assume that after receiving the check, you

\footnotetext{
${ }^{20}$ The label is from David Christensen, "Disagreement as Evidence: The Epistemology of Controversy," Philosophy Compass 4 (2009): 756-767.

${ }^{21}$ Thomas Kelly, “The Epistemic Significance of Disagreement,” in Tamar Gendler Szabo and John Hawthorne (eds.) Oxford Studies in Epistemology (volume 1, 2005), pp. 1167 - 1196.

${ }^{22}$ Adapted from Christensen "Epistemology of Disagreement" and "Disagreement as Evidence" and Kelly "Peer Disagreement and Higher Order Evidence".
} 
didn't just do a quick addition and division in your head, but instead got your calculator out and double-checked the result. You are thus very confident that you determined the right amount each of you owes. In this case, the fact that your friend comes up with a different result gives you no reason to suspend your belief about the correct amount. This variation shows how it can be rational to disregard the opinion of a peer, which is an important point for defenders of the Steadfast View. ${ }^{23}$ But this example only shows how one of the two parties to a disagreement may be justified to stick to her belief, not both. ${ }^{24}$

To get to the case that adherents of the Steadfast view seem to have in mind, we need a further variation that shows how both can be justified to hold two incompatible beliefs. One way to get there is by dropping the assumption that there are only three doxastic states. Assume you are discussing a planned outing for the next day. You agree that you only want to go if the weather is good. You both have a decent understanding of meteorology and studied all available reports and data. You both know that meteorology is an inexact science, however, and so you both attach a degree of credence of less than 1 to the belief you've formed about whether or not it will rain. In addition, let's assume that there is a range of reasonable credences - against Uniqueness. For example, let's assume that given the

\footnotetext{
${ }^{23}$ Note that the Steadfast View is different from the Extra Weight View; see also Elga "Reflection and
} Disagreement". The latter suggests that it is rational to give more weight to your own belief simply because it is yours. The Steadfast View is not person-specific in this sense. It merely suggests that if someone is justified to hold a particular belief given first-order evidence, they are not required to revise their belief if a peer disagrees with them.

${ }^{24}$ On what Elga calls the Right Reasons View, we can explain why it may be rational to disregard opinions of alleged epistemic peers (because they got it wrong), but not why it is possible to have a reasonable disagreement; see "Reflection and Disagreement". As Elga also explains in this article, the Rights Reasons View runs into difficulties in cases where you have no independent evidence that would entitle you to dismiss the opinion of your peer. 
evidence and the state of the art in meteorology, it is reasonable to believe that it will rain both with 0.5 certainty and with 0.9 certainty. It is thus possible that the two of you will disagree about the credence that you attach to your belief that it will rain the following day and perhaps even about whether or not you should go ahead - while each of you is justified to hold the degree of credence that you do. This case illustrates an instance of a reasonable disagreement in which neither party is required to give any weight to the belief of the other.

What is intuitively appealing about the Equal Weight View is that it attaches epistemic significance to the fact that someone who you take to be a peer and who has access to the same body of evidence disagrees with you. This acknowledges our fallibility. But because it takes splitting the difference to be the appropriate response to disagreements among epistemic peers, it leads to skepticism in areas in which there is widespread disagreement. Philosophy itself is just one example. As many critics have pointed out, the Equal Weight View seems to justify more skepticism than there is to go around. ${ }^{25}$

If one takes the Steadfast View, one avoids this skepticism. Since only first-order evidence matters, if others - including epistemic peers - disagree with you, this requires no response. The problem with this view is that it seems to lead to more dogmatism than is desirable. The Steadfast View makes it too easy for you to dismiss the views of others. Contrary to what the Steadfast View suggests, in many contexts, disagreement among peers

\footnotetext{
${ }^{25}$ In response to this problem Christensen has moved away from the extreme position of the Equal
} Weight View. According to the more moderate "Conciliatory" View, you should give independent weight to the fact that someone you take to be a peer disagrees with you, but how much weight you are required to give depends on a range of factors; see Christensen "Disagreement, Question-Begging, and Epistemic SelfCriticism". On Conciliatory Views, see also Elga's careful discussion in "How to Disagree on How To Disagree". Elga's "Reflection and Disagreement" has a response that a defender of the Equal Weight View can give to the scepticism objection. 
does seem to be epistemically significant. The Steadfast view has no account for why this may be so and why some sort of response is warranted. This is because the Steadfast View explains reasonable disagreement as the outcome of unilateral belief formation processes. It describes the possibility that two individuals might each be justified to hold conflicting beliefs. What it disregards is the social context of belief formation, especially the implications of the fact that we are all imperfect epistemic agents. Disagreement among peers may not require the kind of response that the Equal Weight View demands, but to disregard it altogether seems wrong. ${ }^{26}$

But it is not just the implications of each view that trouble me here. It is also the way in which the problem is framed. Both the Equal Weight View and the Steadfast View approach the question whether reasonable disagreement is possible given that all the relevant evidence has been revealed and is available to all sides of the disagreement. The debate then turns on the epistemic significance of higher-order evidence about the beliefs of peers. The question whether, given a body of evidence, reasonable disagreement is possible is interesting, of course. But I do not think that this is the paradigmatic case for complex public controversies - the kind that motivates political liberalism. What seems more typical in public controversies is that the parties to a disagreement struggle with the full disclosure of

\footnotetext{
${ }^{26}$ The Total Evidence View that Kelly proposes makes an attempt to correct for this deficiency of the
} Steadfast View; see his "Peer Disagreement and Higher Order Evidence.” It acknowledges that a disagreement with someone whose judgment you respect may be epistemically relevant, but not in the way that the Equal Weight View envisages. On the Total Evidence View, such disagreements give you additional, higher-order, evidence which you might need to take into account. On the Equal Weight View and Conciliatory Views in general (see previous footnote), you should evaluate and respond to this disagreement independently of the firstorder evidence you have for the belief in question. On the Total Evidence View, by contrast, the disagreement is simply additional evidence, which you need to consider together with the other evidence you hold. As a result, it still makes it easy for you to dismiss the views of a peer, as Kelly admits. 
the evidence - not because of strategic reasons, but because of difficulties that affect their access and ability to share the relevant evidence. ${ }^{27}$

Both Alvin Goldman and Ernest Sosa have recently made contributions to the debate on reasonable disagreement which draw on evidential limitations and which seem promising for understanding reasonable disagreement in public controversies. ${ }^{28}$ I want to use their contributions to put forward what I call the Opacity View. What is distinctive about the Opacity View is that it links the possibility of reasonable disagreement to limits to the full disclosure of evidence.

How should we imagine these kinds of evidential limitations that are at the center of the Opacity View? My answer to this question draws on Goldman's and Sosa's accounts. Sosa focuses on the first-order evidence available to the parties to a disagreement. Sosa argues that the full disclosure assumption is unsustainable for two main reasons. First, the evidence itself is sometimes "too subtle or complex to be noticed and detailed fully" ${ }^{29}$ Sosa discusses Moore's response to the skeptic to illustrate the difficulty that may affect the available evidence. Moore's argument starts with the knowledge of his hands before him and concludes from that that the external world exists. The skeptic challenges this by pointing out that Moore might be dreaming. Sosa's comment on this debate is this:

\footnotetext{
${ }^{27}$ In terms introduced by Jennifer Lackey, although they may be cognitive peers, they are not “evidential peers”; see Lackey “What Should We Do When We Disagree?”, in Tamar Szabó Gendler and John Hawthorne (eds.) Oxford Studies in Epistemology (Oxford: Oxford University Press 2010), pp. $274-93$.

${ }^{28}$ Alvin Goldman, "Epistemic Relativism and Reasonable Disagreement," in Richard Feldman and Ted A. Warfield (eds.) Disagreement (Oxford: Oxford University Press, 2010), pp. 187 - 215 and Ernest Sosa, “The Epistemology of Disagreement," in Adrian Haddock et al. (eds.) Social Epistemology (Oxford: Oxford University Press, 2010), pp. $278-297$.

${ }^{29}$ Sosa, "The Epistemology of Disagreement," p. 290; italics omitted.
} 
"Moore does not claim it to be obvious that he is awake and not dreaming, so that he needs no ulterior reasons for so believing. On the contrary, he claims that he cannot expound his reasons fully, because they are too extensive and complex."30

This may be a relatively simple case, but the evidence is already too complex to be readily shared. Public controversies typically concern much more complex cases and we should expect that the evidence involved will be very hard, if not impossible, to process fully.

A second difficulty with the full disclosure assumption at the first-order level arises because, as Sosa notes, our beliefs form "in us over time through the subtle influence of diverse sources". ${ }^{31}$ These sources include factors such as socialization, environment, etc. Because our beliefs form gradually over time, in response to a multitude of contexts and social interactions, we tend to not be aware of all the influences that led us to hold a particular belief. This type of evidential limitation seems also highly relevant for public controversies.

I shall pursue the relevance of both these sources of difficulties that affect our access to and sharing of relevant evidence in public controversies in the final section. For the time being, let me just note that rational, well-intentioned individuals who try hard to disclose the evidence available to them and to overcome their disagreement, but who are constrained by the nature of the evidence and of their belief formation processes, may justifiably reach diverging conclusions based on the differences in evidence available to them. This suggests one explanation for the possibility of reasonable disagreement.

A reasonable disagreement can also arise if the two individuals consider the same body of first-order evidence but use different systems of epistemic norms to justify their beliefs. A second explanation for reasonable disagreement on the Opacity View focuses on

\footnotetext{
${ }^{30}$ Sosa, "The Epistemology of Disagreement," p. 288; italics omitted.

${ }^{31}$ Sosa, "The Epistemology of Disagreement," p. 290; italics omitted.
} 
evidential limitations that affect the justification of systems of epistemic norms. I follow Goldman here who argues that the justification of beliefs is necessarily pegged to a system of epistemic norms. Assume there is ultimately only one correct system of epistemic norms call it $\mathrm{E}^{*}$. But it does not follow from the fact that there is such a system that people will automatically be justified to use this system. To the contrary, they may be justified to use less than perfect systems E or E'. As Goldman explains:

"In general, it doesn't follow from the truth of an arbitrary position P that everybody or anybody is justified in believing P. Some truths are hidden; they don't automatically generate evidence of their truthfulness to populations, or any populations. Gaining epistemic access to them may be difficult and problematic. Truths concerning E-systems are likely to be in this boat." 32

Evidential limitations at the level of systems of epistemic norms may be such that at least some persons, and possibly all of them, lack access to the evidence they would need to be justified to use $\mathrm{E}^{*}$. The evidence they have may justify them to use less than perfect systems E, E', etc. ${ }^{33}$ Suppose there are two persons, one is justified by the available evidence to use the system $\mathrm{E}$ and the other is justified to use system E'. It is then possible that after considering the same body of first-order evidence they will each be justified - by the system

${ }^{32}$ Goldman, "Epistemic Relativism and Reasonable Disagreement," p. 196f.

${ }^{33}$ Goldman, "Epistemic Relativism and Reasonable Disagreement," p. 201, describes the resulting position - he calls it "objectivity-based relativism" as follows: "There is a uniquely correct E-system that governs the objective justifiedness and unjustifiedness of people's doxastic attitudes. However, people occupy different evidential positions vis-a-vis this system and other candidate E-systems. Hence, the objective justificational status of different people vis-a-vis different E-systems is varied rather than uniform. Some people are objectively justified in believing certain E-norms and E-systems to be correct; others are objectively justified in believing other E-norms and E-systems to be correct. Similarly for attitudes other than full belief toward Enorm-related propositions." 
of epistemic norms they use - to hold to mutually incompatible beliefs. If that is the case, we again have a reasonable disagreement.

What drives the debate between defenders of the Equal Weight View and the Steadfast View is the question what, if anything, follows from the fact that an epistemic peer disagrees with you. Disagreement is reduced to the tension between the beliefs that the two parties hold. The Opacity View adds another dimension - that of a tension between the evidence bases for their first-order beliefs or for the system of epistemic norms they use. The thought is not, of course, that the parties simply happen to use a different evidence basis. That would be a trivial account of reasonable disagreements. The thought is also not simply that one person is "seeing things" that are not there, or that one person is failing to grasp evidence that is presented to her. As Feldman has rightly pointed out, in such cases at least one person is being irrational and hence we're not dealing with a reasonable disagreement. ${ }^{34}$ The key claim is, rather, that the nature of the evidence and/or of belief formation processes may be such that the parties to a disagreement cannot fully access and share the evidence that would be necessary for the disagreement to be resolved. It is thus possible that rational individuals continue to disagree even after extensive and open discussion of their views.

In sum, on the Opacity View, if two persons who regard each other as epistemic peers struggle to access and share evidence that is relevant for the justification of the beliefs they hold, a reasonable disagreement is possible.

Assume there is a disagreement between two peers. And they struggle to fully disclose the evidence they have for their beliefs. They thus find themselves in a potentially reasonable disagreement. How should they respond to each other? The first step is to eliminate the possibility that what divides them is a mere disagreement, i.e. one that arises

\footnotetext{
${ }^{34}$ Feldman, "Reasonable Religious Disagreements".
} 
from only apparent opacity and one that can be eliminated once they have been able to fully disclose the evidence on which their beliefs are based. But assume deliberation fails to produce an agreement and they still don't have any independent information which would suggest that they could simply dismiss the belief of their peer. The remaining disagreement can arise for two reasons: it is either related to problems with accessing and sharing the evidence they have for their beliefs - at the first-order level or at the level of evidence for systems of epistemic norms - or it is related to how they respond to the evidence they share. Assume there is no problem in how they have responded to the evidence that they share and that they are both aware of that. The remaining disagreement is then due to differences in the evidence that they have for the beliefs they hold. Also assume that there is no problem with how they have each responded to the evidence that they have not been able to access and share. So before they became aware of their disagreement, they were each justified to hold the beliefs they did.

Does the fact of a disagreement which remains even after extensive deliberation change something about their situations? I think the answer is yes. ${ }^{35}$ This is because their

${ }^{35}$ Note that I'm going beyond Goldman's and Sosa's accounts here. Goldman only discusses the possibility of how a reasonable disagreement might occur, but not how two people who take each other as peers should respond to the fact of a disagreement. In other words, he takes a synchronic perspective to peer disagreements. I'm interested here in the diachronic perspective. See Goldman "Epistemic Relativism and Reasonable Disagreement," p. 209 for a discussion of this distinction. Sosa defends a view that has some parallels to the Steadfast View. He argues that if you're reasonably sure that you've correctly responded to the evidence you have, then the fact that you haven't been able to use that evidence to show that your opponent is wrong gives you no reason to diminish confidence in your view. What Sosa does not address, however, is the question of what follows from the higher-order evidence that you get from a peer disagreement about the adequacy of your evidential basis (as opposed to the adequacy of how you've responded to the evidence you have). If the disagreement concerns subjective facts - e.g. about your hands, your dreams, or your experience of 
disagreement is epistemically significant, but in a different sense than on the Equal Weight View. What follows from the Opacity View is that they each must take into account that there is a tension in the evidential bases on which their respective beliefs are based, directly (firstorder level) or indirectly (level of epistemic norms). If the problem affects first-order evidence and if Uniqueness applies, then the evidence that they jointly hold - but fail to fully access and share - would suggest a particular belief. They don't know which belief that would be, of course. This gives each of them a reason to diminish confidence in their original beliefs somewhat. ${ }^{36}$ If they consider the same body of first-order evidence and the problem affects the evidence at the level of the systems of epistemic norms that they each use, it is again Uniqueness which gives them a reason to diminish confidence in their respective beliefs. This is because Uniqueness, if it applies, would warrant a unique belief for the evidence they consider. Their remaining disagreement reveals to them that at least one of them is not using the perfect system $E^{*}$ and possibly both of them aren't. Again, they don't know which system is $\mathrm{E}^{*}$ and this gives each of them a reason to diminish confidence in the justificatory power of the system of epistemic norms that they use and hence a reason to diminish confidence in their original belief. In both cases, the remaining disagreement is a reasonable disagreement.

pain - this view may have some plausibility. In this case, you may well be entitled to downgrade your opponent's view. But if the disagreement is about objective facts, a disagreement with a peer should lead you to question the evidence basis that you hold.

${ }^{36}$ This may sounds false with regard to disagreements about purely subjective facts, i.e. facts that only concern a particular person and for which evidence is only accessible to that person, but it is hard to see how there can be a reasonable disagreement about such facts in the first place. It is more likely that there is no justification for the belief about the subjective fact of the other person. 
How much should they diminish confidence in their original beliefs? I do not have a principled answer to this question. But the following boundaries apply. The Opacity View identifies a middle ground between the skepticism implied by the Equal Weight View and the dogmatism implied by the Steadfast View. This is one of the advantages of the Opacity View. It avoids skepticism - and spinelessness ${ }^{37}$ - because the evidential basis may be such that you have some justification to hold a belief even if someone you take to be an epistemic peer disagrees with you. It also avoids the dogmatism of the Steadfast View because, unlike the latter, it offers an explanation for why a reasonable disagreement might occur between two people who regard each other as peers.

On the Equal Weight View, a disagreement with someone you take to be a peer implies that you need to adjust your belief in direction of the other by splitting the difference. This crowds out the possibility of a reasonable disagreement. On the Steadfast View, a reasonable disagreement is possible, but it is the unintended consequence of two persons being independently justified to hold what are incompatible beliefs, for example because the evidence permits a whole range of beliefs. On the Opacity View, likewise, a reasonable disagreement is possible, but a reasonable disagreement is characterized by the remaining difference after the peers have each responded to the fact of a disagreement between them and adjusted their beliefs. ${ }^{38}$ The need to respond to a disagreement with a peer arises from the discrepancy in the grounds that justify beliefs that such a disagreement reveals. If the evidential bases cannot sufficiently be shared and assessed so as to generate a unique correct belief, both need to attribute some probability to the possibility that all the relevant evidence,

\footnotetext{
${ }^{37}$ Elga "Reflection and Disagreement".

${ }^{38}$ In this respect, the Opacity View resembles both the Conciliatory View and the Total Evidence View
} (see footnotes 25 and 26 above). 
if it had been shared, would justify a different belief. This gives them reason to diminish confidence in their original belief.

The upshot of a reasonable disagreement as characterized by the Opacity View is that each has reason to accept the disagreement and to be tolerant of the view of the other. As explained, this pluralism doesn't arise, as in the Steadfast View, from a shared body of evidence permitting different beliefs, but from the fact that the relevant evidence cannot be fully accessed and shared. This way of understanding reasonable disagreements has implications for epistemic authority. Whereas the Steadfast View anchors epistemic authority in how each person individually responds to the available evidence, on both the Equal Weight View and the Opacity View, as I have described it, epistemic authority may have to be shared in the sense that each party to the disagreement has to acknowledge the other as a potential epistemic authority. But whereas the way in which Equal Weight View requires that peers respond to each other eliminates the possibility of reasonable disagreements, on the Opacity View, they may remain.

\section{$\underline{\text { An Epistemic Argument for Public Justification }}$}

Based on the Opacity View, I now want to argue for the following: (i) reasonable disagreement about the premises involved in the justification of political institutions is possible; and (ii) if such reasonable disagreement is possible, then public justification of political institutions is necessary for legitimacy.

I start from the assumption that there are fundamental moral and/or religious truths and that beliefs about such truths have a bearing on many public controversies. By fundamental truths, I mean those related to salvation or perfection and I am assuming that 
they are attitude-independent. I am thus granting the metaphysical claim that moral realists make. $^{39}$

Rawls, of course, did not reject moral realism. On his view, political liberalism implies that people ought to bracket their commitments to fundamental moral and/or religious truths in public justification, not that there are no such truths. According to Rawls, this need for epistemic abstinence arises from the absoluteness of the claims made in the name of these truths. He gives a historical reference to the Reformation and the emergence of competing religions to motivate this way of thinking. Rawls writes:

"What is new about this clash [between different religions] is that it introduces into people's conceptions of their good a transcendent element not admitting of compromise. This element forces either mortal conflict ... or equal liberty of conscience and freedom of thought. ... Political liberalism starts by taking to heart the absolute depth of that latent conflict." ${ }^{, 40}$

The problem with this way of understanding political liberalism is that it is unable to escape the dilemma it is supposed to avoid. If we link the "transcendent element" in comprehensive conceptions of the good to a type of knowledge that is purportedly absolute yet plural, then violent conflict is already embedded in political liberalism. The gloss of toleration that is supposed to hide this conflict will prove too thin. I suppose it is a worry of this sort which has lead some of Rawls' critics to argue that if the possibility of absolute

\footnotetext{
${ }^{39}$ For a helpful classification of different claims typically associated with moral realism, see Stephen
} Finlay, "Four Faces of Moral Realism," Philosophy Compass 2 (2007): 820 - 849. What I am endorsing here is the metaphysical claim. This assumption of moral realism distinguishes my approach from that taken by Christopher McMahon, Reasonable Disagreement: A Theory of Political Morality (Cambridge: Cambridge University Press, 2009).

${ }^{40}$ Rawls, Political Liberalism, p. xxvi. 
knowledge of fundamental truths is acknowledged, then we might as well bite the bullet and use this knowledge in our defenses of the requirements of legitimacy and justice.

My take on political liberalism is different. Based on the epistemology of disagreement, and specifically the Opacity View, I shall argue that we have reason to be cautious about the epistemic authority that our beliefs about fundamental moral and/or religious truths give rise to. The nature of the evidence we have for such truths and how we form beliefs about them make it very difficult - if not impossible - to access and share the evidence and to assess our response to the evidence that we have. My point will be that it is because of these constraints on the full disclosure of evidence that a commitment to moral realism does not undermine the idea of political liberalism. In other words, I want to show that public justification is the best response that we have to the epistemic circumstances that we face in the political realm. It is not plausible to simply ask people to bracket what they believe is true. Instead, it has to be explained why the epistemic circumstances imply that the justification of political institutions has to be public.

Let me explain what I have in mind by focusing on the case of religious truths first. To get a grip on the kind of limitations that affect our access to and ability to share evidence for our beliefs about such truths, it is helpful to bring to mind William James' distinction between personal and institutional religion. Personal religion captures "the feelings, acts, and experiences of individual men in their solitude, so far as they apprehend themselves to stand in relation to whatever they may consider the divine". ${ }^{41}$ Personal religion relies mainly on first-order evidence in the form of experience. Religious doctrines, by contrast, represent institutional religion. Evidence for them relies "second-hand upon tradition", as James puts it. $^{42}$ The thought behind this distinction, which has had much influence on debates on the

\footnotetext{
${ }^{41}$ William James, Varieties of Religious Experience (New York: Penguin, 1982), p. 31.

${ }^{42}$ James, Varieties of Religious Experience, p. 30.
} 
epistemology of religion, is that insofar as there is any access to fundamental religious truths it is through personal experience. While the founders of religious doctrines are likely to have been inspired by personal religious experience, the doctrines themselves are only incomplete attempts to capture the fundamental religious truths thus experienced.

This account, which strikes me as plausible, allows us to see that evidential limitations affect beliefs about religious truths at two levels - in accord with how I've presented the Opacity View. First, personal experience is of truths that are very difficult, if not impossible, to articulate. This first problem has its origin in the subtlety and complexity of the first-order evidence for religious truths. Second, attempts to share this experience with others, through the arguments, narratives, images, etc. contained in religious doctrines, lack the immediacy of the personal experience. Although these attempts aim at establishing a kind of system of epistemic norms capable of producing correct beliefs about fundamental religious truths, something is lost in translation. This second problem can be described in terms of Goldman's distinction mentioned above between the correct system of epistemic norms $\mathrm{E}^{*}$ - the religious doctrine that is uniquely able to produce correct beliefs about these truths and - imperfect, yet permissible systems of epistemic norms E, E' etc.. The second problem is that we lack the evidential basis to identify $\mathrm{E}^{*}{ }^{43}$

The evidential limitations that operate at the level of personal experience and at the level of religious doctrines are amplified by the fact that we tend to be socialized into

\footnotetext{
${ }^{43}$ Mark Johnston has recently argued a similar point. As he puts it in Saving God (Princeton: Princeton University Press, 2009), p. 10: "What could possibly count as evidence that you believe in God [and not in an idol]? It can seem surprising that this question can be asked. But it is even more surprising that the answers are not ready to hand." Because of these evidential difficulties, “[t]he best thing a believer can say in response to the question 'Do you believe in God?' is 'I can only hope I do. I can only hope that I actually stand in a tradition [a religious doctrine] in which God has genuinely revealed himself".
} 
particular religious doctrines (as believers or as skeptics). We thus face the additional difficulty of trying to separate our personal experiences and our judgments about religious doctrines from the influences of socialization and this further limits our abilities to access the evidence we have for our beliefs and hence our ability to share our evidence with others.

So much for the case of religious truths: even if we grant that there are such fundamental truths, we may still find that evidential limitations - at first-order level or at the level of systems of epistemic norms - affect our ability to reach an agreement on what the correct belief is. I think the case of moral truths is analogous. The first-order evidence we have about moral goodness and rightness is through intuition and personal experiences. These intuitions then form part of the evidential basis for moral doctrines (and of claims about the relationship between moral and religious truths). It is broadly acknowledged that all moral doctrines rely to some extent on intuitions. The use of intuitions may be limited to motivate a small set of foundational principles or more extensive as in the self-declared intuitionist moral theories. It is also fairly broadly acknowledged that these intuitions may be fallible and influenced by a wide range of factors, including, like in the case of religious experiences, the doctrines into which we are socialized. In other words, we cannot simply assume that these intuitions will reveal correct beliefs about fundamental moral truths. But even insofar as they do, the beliefs they give rise to need articulation in the form of a moral doctrine in order to be assessed and shared. And this articulation introduces an interpretative gap, describable as the gap between a (justified) system $\mathrm{E}$ and the uniquely correct system $\mathrm{E}^{*}$. In light of the many examples of wrong beliefs about fundamental moral truths that can be found throughout our history and of the many ongoing debates in normative ethics, I think it is safe to say that we lack the evidence to conclusively determine a doctrine - a system of epistemic norms uniquely capable of producing correct beliefs. I do not intend to imply that all moral and/or religious doctrines are necessarily equally valuable - some may get closer to the truth than 
others. But I want to claim that it is easier to say which system of epistemic norms is not the correct one than to positively identify the system which would generate correct beliefs.

What I have discussed are general features of the evidence for moral and/or religious truths and of our belief formation process in this regard. It is plausible to think that people are equally positioned vis-à-vis these constraints and this suggests that they may plausibly regard each other as epistemic peers. Remember, a peer is someone who is equally likely to make a mistake in a particular matter. This notion of peerhood is compatible with significant epistemic inequalities, both with regard to training and qualifications and with regard to expertise on different topics. What makes it plausible for us to regard each other as peers with regard to claims about fundamental moral and/or religious truths is that the obstacles to forming correct beliefs about these truths and to identifying the correct doctrine $\mathrm{E}^{*}$ that I've just discussed lie in the nature of those truths themselves and not in person-specific factors. Since these obstacles affect our ability to access and share first-order evidence for moral and religious beliefs and evidence for moral and religious doctrines, we get to the possibility of a reasonable disagreement as understood on the Opacity View.

The Opacity View implies that in a persisting disagreement about fundamental moral and religious truths between parties who don't have any independent reasons to think of themselves as more likely than everyone else to form correct beliefs, each party must diminish the confidence they have in their views. This is because of limitations that affect their abilities to access and share the evidence relevant for the justification of these beliefs either at the first-order level or at the level of evidence for different doctrines understood as systems of epistemic norms. While both parties to such a disagreement may be entitled to continue to hold on to their beliefs, they each also need to take into account that even if they have some justification to hold their beliefs about moral and/or religious truths, neither is entitled to simply dismiss the beliefs of their opponent and insist on the correctness of their 
own belief and each must allow for the possibility that the view of the opponent is correct but that they have not been able to present the necessary evidence for why this is so.

What the argument so far shows is that reasonable disagreement about fundamental moral and/or religious truths is possible. And the appropriate response to reasonable disagreement, as argued above, is to accept pluralism. As long as we have strong first-order evidence for particular beliefs or operate with a robust system of epistemic norms and our opponents have failed to present evidence in favor of their views or of the system of epistemic norms they use, it is not necessary that we suspend belief. But we must accept that our opponents may have good reasons to hold the beliefs they do, even if they differ from ours. The Opacity View thus explains the possibility of an irreducible pluralism based on reasonable disagreements.

The next step of my argument shows how reasonable pluralism, thus understood, warrants public justification. This is so on grounds of legitimacy. As mentioned, I am working here with an understanding of legitimacy which requires that basic political institutions (the constitutional essentials) are justified. Justification in this context means that there are sufficient reasons for the citizens to accept a particular set of political institutions that is operative in a political community and, by implication, to comply with the decisions made within them. The problem that reasonable disagreements about particular claims pose is that they undermine attempts to justify political institutions that involve these claims.

To see why, assume, for the sake of argument, there is a reasonable disagreement with regard to a claim $\mathrm{p}$, for example 'a responsible leader follows God's will'. In a reasonable disagreement, both parties to the disagreement are justified to hold the belief they do. If the Opacity View is correct, the disagreement arises because of difficulties they have to access and share evidence for the claim in question. This gives each of them reason to diminish confidence in their beliefs and to acknowledge the possibility that the belief of the other party 
might be correct. If there is such a reasonable disagreement, neither p nor not-p can be used in the justification of political institutions. If $\mathrm{p}$ is used, the party that justifiably beliefs not-p will not regard the institution as justified. If not-p is used, the opposite occurs. So if there is a reasonable disagreement about whether or not 'a responsible leader follows God's will', then attempts to justify the expansion of the political authority of the executive branch of government based on that controversial claim will fail.

Mere - not reasonable - disagreement does not undermine the justification of political institutions, of course. In the case of mere disagreement, the parties involved need to consider the evidence again, with good intentions and in the best way they can. The disagreement is then either resolved or redefined as a reasonable disagreement. In a reasonable disagreement, as discussed, accepting pluralism is the appropriate response.

Importantly, if reasonable disagreement is possible, then it will not be sufficient to address attempts to justify political institutions to rational persons per se. Instead, such attempts must be addressed to the epistemic peers in question, factoring in the possibility that they will have reasons to disagree. ${ }^{44}$

\footnotetext{
${ }^{44}$ What we get is justification from a second-person standpoint. Stephen Darwall defines the second-
} person standpoint in ethics as "the perspective you and I take up when we make and acknowledge claims on one another's conduct and will'. Stephen Darwall, The Second-Person Standpoint (Cambridge Harvard University Press, 2006), p. 3. In Darwall's account, the second-personal standpoint is limited to the realm of ethics. On his view, epistemic claims are ultimately third-personal. The epistemology of disagreement draws this asymmetry between the ethical and epistemic realms into question. It reveals that there are epistemic contexts in which it is also appropriate to take a kind of second-person standpoint. What I have in mind is the shift from claims that take the form of what anyone has a reason to believe - with epistemic authority not depending on the relationship between epistemic agents - to claims that anticipate the possibility that two epistemic peers are each under an obligation to acknowledge the other as a potential epistemic authority. At the same time, since at most one of them can be correct, epistemic authority does not depend solely on the relationship between (epistemic) 
The argument from reasonable disagreements thus explains the significance of public justification for political liberalism. When there is reasonable disagreement about fundamental moral and/or religious truths, attempts to justify political institutions based on beliefs about such truths will not be successful. If reasonable disagreements about moral and religious truths are possible, those involved must acknowledge the claims others make on them as potential epistemic authorities. This establishes why the justification of constitutional essentials must be justification by and addressed to all members of the political constituency.

Public justification of constitutional essentials will be successful if it is based on beliefs about which people do not reasonably disagree. What kind of beliefs could that be? I think that as philosophers we can merely speculate about the basis for such a convergence. The Rawlsian solution is to refer to fundamental political values. Rawls argued that values implicit in the political system that people uphold allow them to overcome what I have defined as reasonable disagreements. But shared political values need not be the only basis. We can imagine other higher-order interests - e.g. an interest in coordination when spheres of activity overlap - to suggest possibilities for overcoming reasonable disagreements. The general thought is that the chances for avoiding reasonable disagreement are better with regard to beliefs that do not refer to fundamental moral and/or religious truths but to political norms and practices that we construct to achieve coordination even in circumstances of pluralism. Since the main topic of my paper has been to explain why public justification is significant, however, I have to leave the question of what the success conditions are for public justification for another paper.

agents, but is also connected to truths existing outside of this relationship. In this respect, the kind of secondperson standpoint invoked here differs from the one Darwall invokes in the context of ethics. I've developed this argument in Fabienne Peter "The Procedural Epistemic Value of Deliberation", Synthese forthcoming (DOI: 10.1007/s11229-012-0119-6). 